\title{
Design of Hardware-in-the-loop Simulation Platform in Propulsion Control Systems of Aero-Engine
}

\author{
Bei Yang ${ }^{1, a}$ and Xiaowu Ding ${ }^{1, b}$ \\ ${ }^{1}$ School of Aircraft Engineering, Nanchang Hangkong University, Nanchang 330063, China \\ apeipeiyang99@sina.com, ${ }^{\mathrm{b}} 48040 @$ nchu.edu.cn
}

Keywords: Aero-engine; Hardware-in-the-loop; System simulation; SPI communication; CRC verification

\begin{abstract}
The performance of the electronic controller is of significance to the development of turbofan engine with afterburner. To verify the feasibility of the control algorithm and the design scheme of hardware and software of the controller, the embedded computer based on PC104 architecture was used as the electronic controller, the C8051F320, ADuC7020, and ACEX1K50 microprocessors were adopted as the signal interface regulate box of the engine model computer. The $\mathrm{C}$ and VHDL language were employed to develop the system, a simulation experimental platform of hardware-in-the-loop was thus designed. Simulation results of hardware-in-the-loop show that the controlled parameter of the engine tends to the final expected value, and the fidelity of the signal transmission of the physical quantities between the electronic controller and the engine digital model is favorable.
\end{abstract}

\section{Introduction}

Hardware-in-the-loop simulator of engine is a full-state and full-envelope simulated test which is based on engine mathematical simulation model and some entities as controller, sensor, and actuator is switched in the loop. The test is conducted on ground to control the system. [1,2]The core system of hardware-in-the-loop simulator in aero-engine is made up of engine model computer, all kinds of conditioning interface boxes for controlling signal, and engine electronic controller[4], as show in Fig. 1.

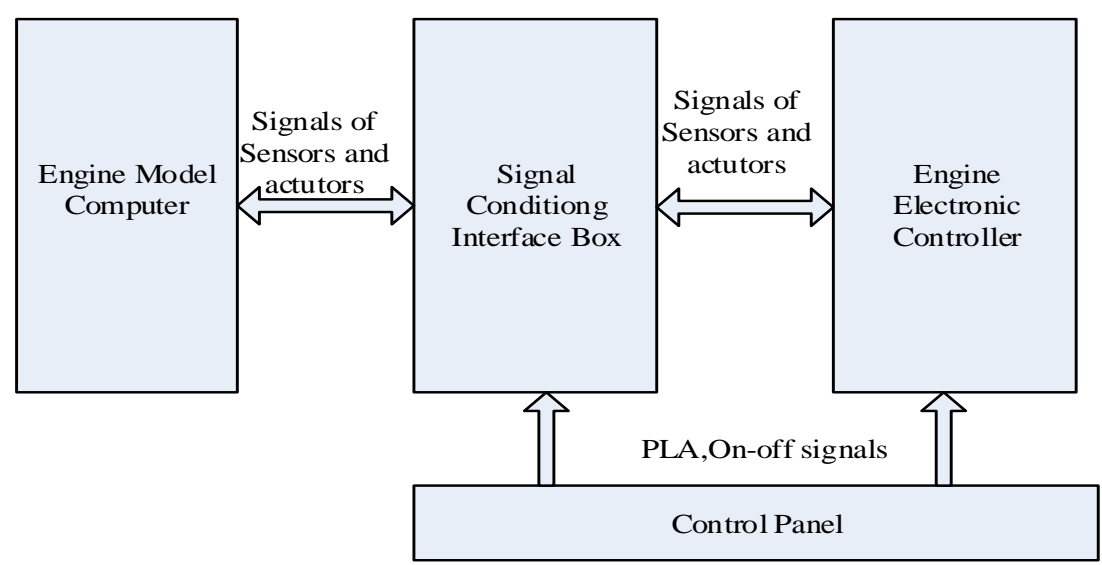

Figure 1. Hardware-in-loop simulator frame of aero-engine

\section{Hardware-in-the-loop Structure}

As a bridge between engine model computer and electronic controller in the whole simulator design, signal conditioning interface box converts status messages of engine's digital quantification formed by engine digital model to real physical quantity signal recognizable for the electronic controller of engine and also converts status and control signal of actuator to digital quantification 
signal recognizable for computers. No simulation field as temperature field and pressure field is included in the design of simulation platform and there is no all kinds of actuators and oil supply systems. But verification of the digital-electronic controller of engine can be conducted under basic condition. Due to the flexibility of signal conditioning box, the external expansion of all kinds of measuring systems and actuators of simulated source and sensor is allowed. The whole control system structure is shown in Fig. 2.

Table 1 Nomenclature

\begin{tabular}{|c|c|}
\hline PLA & power lever angle \\
\hline T1 & turbine inlet total temperature \\
\hline P1* & turbine inlet total pressure \\
\hline P31 & core pressure \\
\hline T6 & mixed turbine discharge temperature \\
\hline P6 & mixed turbine discharge pressure \\
\hline N2 & low pressure rotor speed \\
\hline N1 & high pressure rotor speed \\
\hline a1 & fan vanes angle \\
\hline a2 & compressor inlet variable vanes angle \\
\hline A8 & exhaust nozzle throat area \\
\hline mf & main fuel low \\
\hline mfaf & after-burner fuel low \\
\hline
\end{tabular}

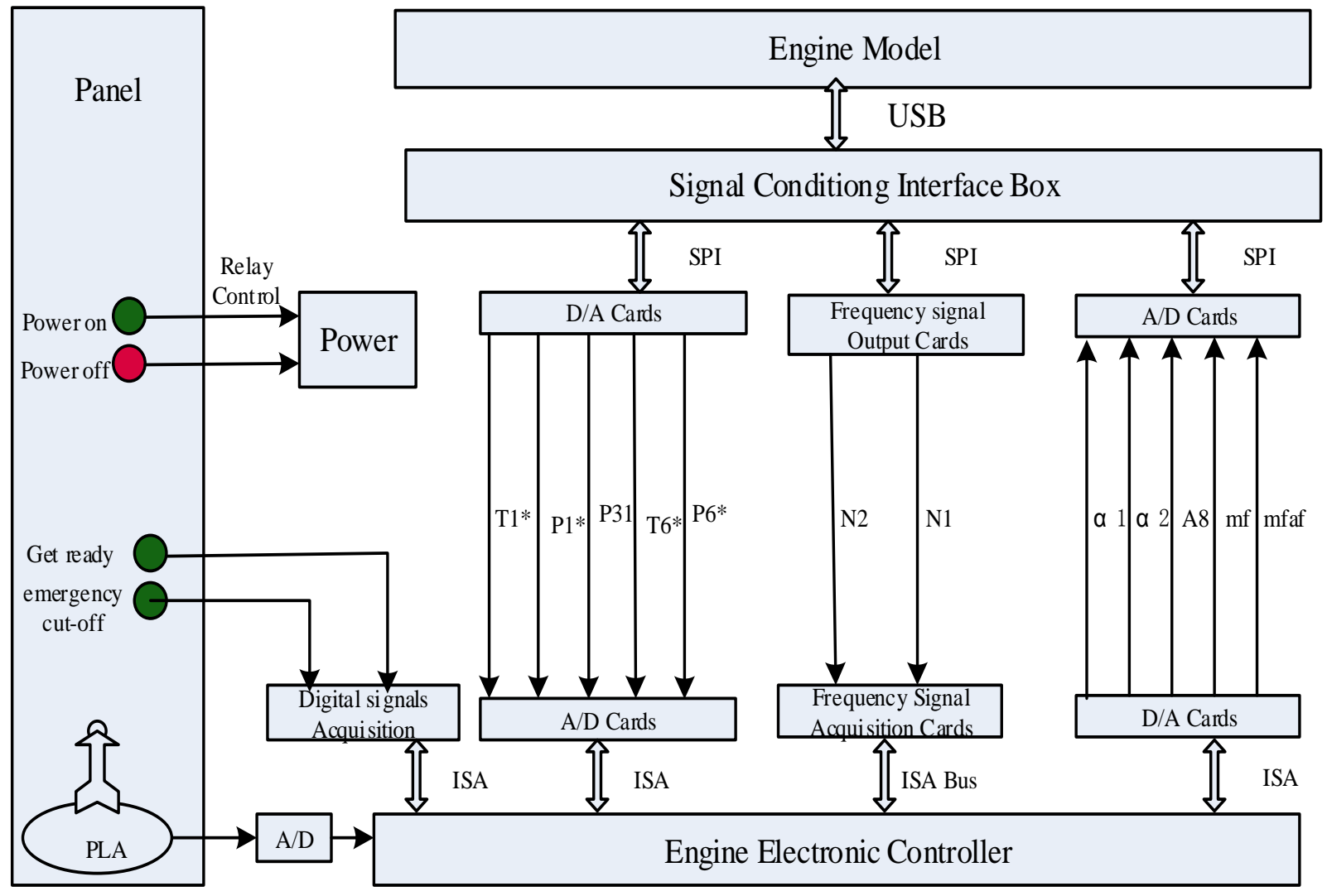

Figure 2. Structure diagram of hardware-in-loop simulator platform

\section{Digital-electronic Controller}

Seen from the current research status at home and abroad, aircrafts whose size is over 1 meter normally adopt embedded microcomputer or DSP as the core unit of measurement and control. 
SysCentreModule/PMI template come from ShengBo Company is adopted in this system. Electronic controller shall gather physical quantities such as total temperature at the entrance of engine $\mathrm{T} 1 *$, total pressure at the entrance of engine $\mathrm{P} 1^{*}$, static pressure at the exit of high-pressure compressor $\mathrm{P} 31$, total temperature at the exit of turbine $\mathrm{T}^{*}$, total pressure behind the turbine $\mathrm{P} 6^{*}$, high-pressure rotor speed N2, low-pressure rotor speed N1, and throttle lever angle PLA. Control signals which should be output by electronic controller include main fuel flow $\mathrm{mf}$, reheat fuel flow mfaf, adjustable blade angle at fan inlet $\alpha 1$, adjustable stator blade angle at the entrance of compressor $\alpha 2$ and controlled quantity of jet nozzle area A8 [4].

Software system of electronic controller covers two main parts: interface program and control program. Interface program completes functions of analog acquisition, physical parameter display(temperature, rotate speed, pressure, time), analog signal transmission, frequency acquisition, generation of PWM and frequency signal, system self-inspection, fault diagnosis, safety protection, initialization of software and hardware of system, keyboard inspection, communication with computer, timing sampling, digital filtering, linear processing, and scale transfer. Control program is in charge of corresponding homeostatic control, transient state control and overheat and over-running protection of the engine. The flow chart is shown in Fig. 3.

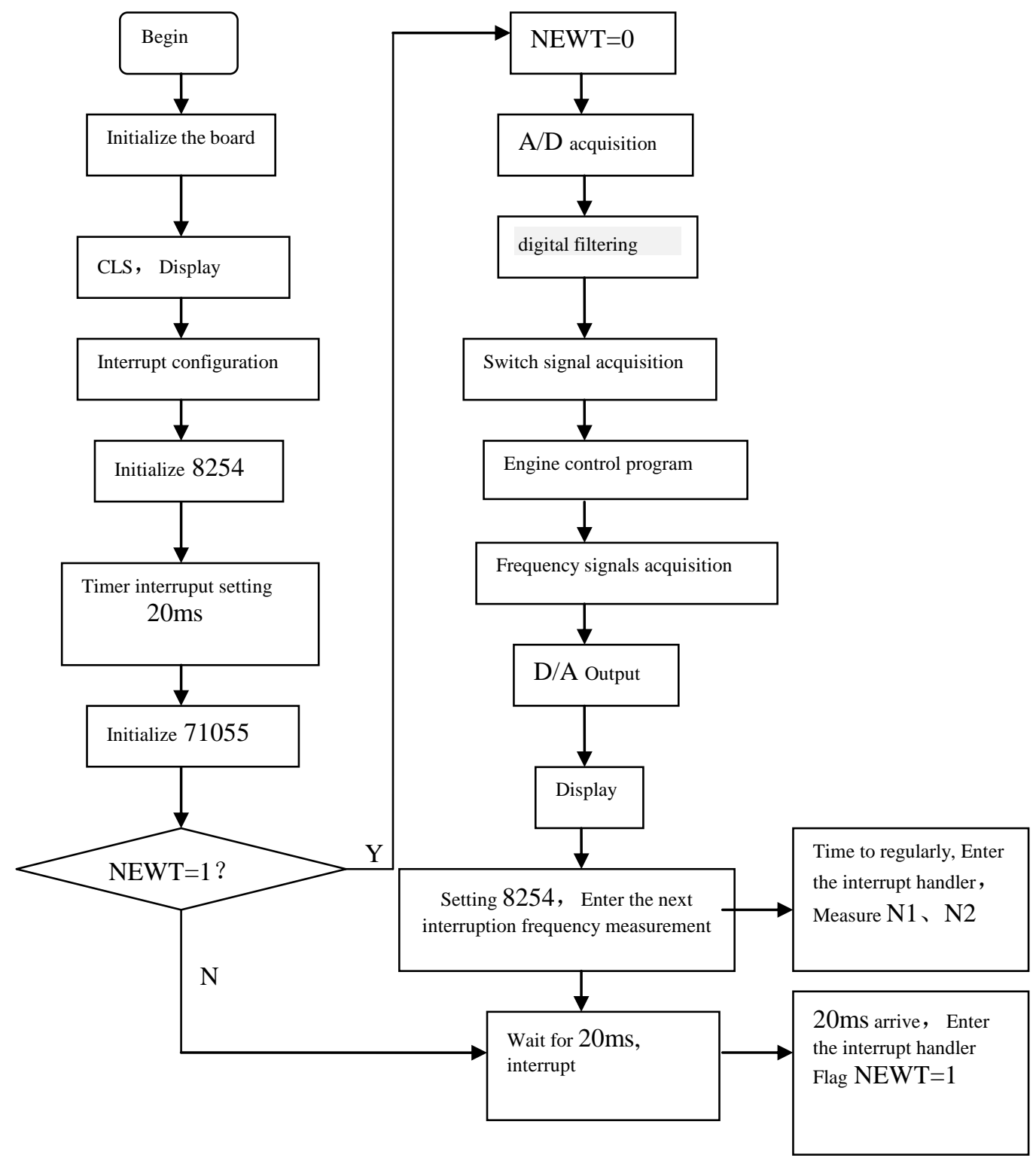

Figure 3. Main program flow chart of electronic controller 


\section{Design of Signal Conditioning Interface Box}

A main control circuit board communicating data with engine model computer and some boards, directly connected with electronic controller, for generating and gathering physical quantity signals are set in the signal conditioning interface box. Such as gathering temperature signal measured by thermocouple, and rotate speed signal measured by photoelectric velometer, PWM signal of stepping motor whose output drives pump rotation etc [5]. The structure is shown in Fig. 4.

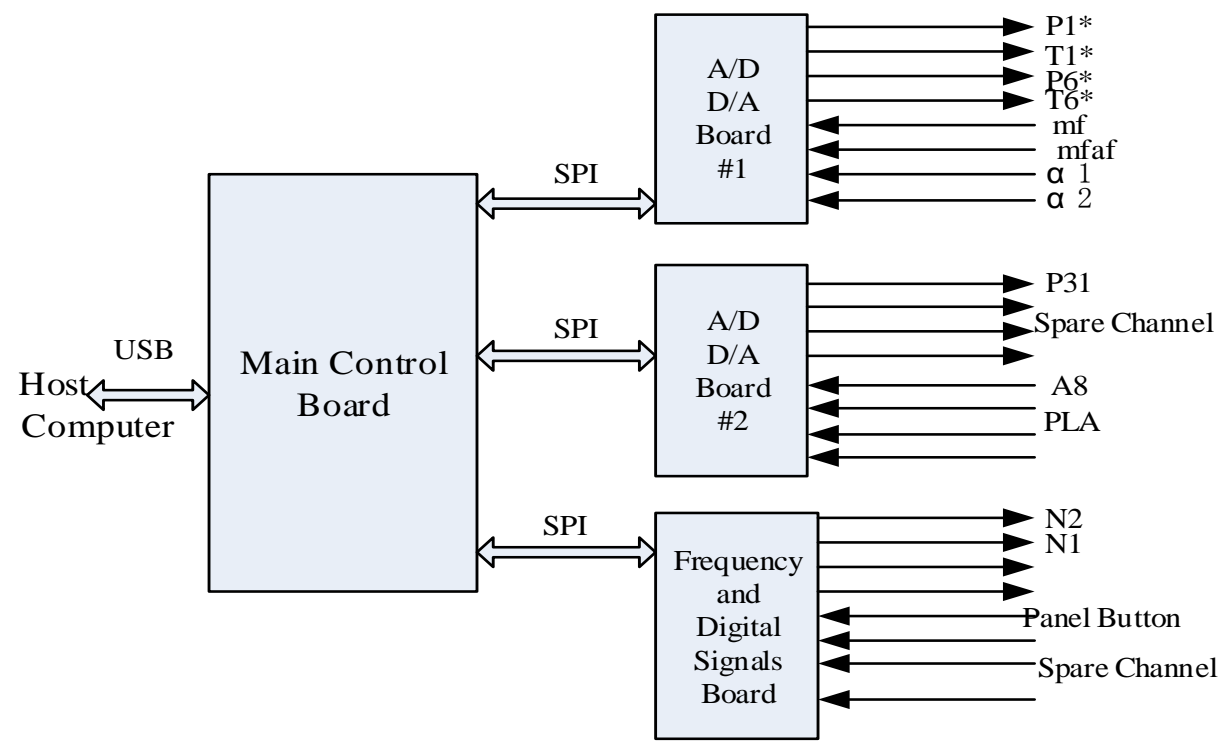

Figure 4. Structure diagram of signal conditioning interface box

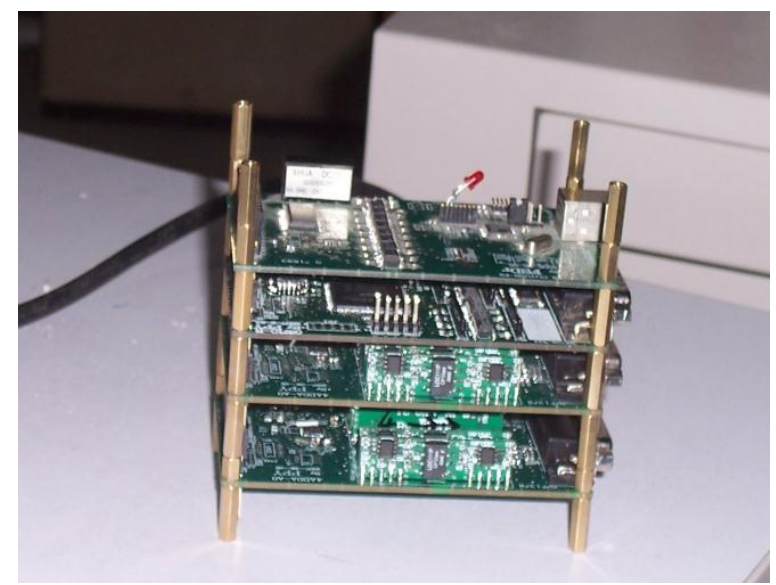

Figure 5. Signal conditioning interface box

Master Control Board. Master control board is in charge of communicating with upper computer by USB2.0 and transfers the data of engine model computer to each signal conditioning board. Master control board also control the movement of each conditioning board through SPI bus. Combining all these functions, C8051F320 chip produced by Silicon Laboratories is chosen by master control board.

Frequency Signal Acquisition and Output Board. Generally, ground test stand of the engine measures the rotate speed of electrical machine or oil pump through photoelectric speed sensor to calculate high-pressure and low-pressure rotor speed of the engine. Signal obtained is the pulse signal of frequency change. The designed simulator makes use of FPGA to generate variable square signal to simulate the rotate speed given by model machine [3]. Meanwhile, pulse signal generated by 
electronic controller shall be measured and reported back to model machine. Functional block diagram of board is shown in Fig. 6.

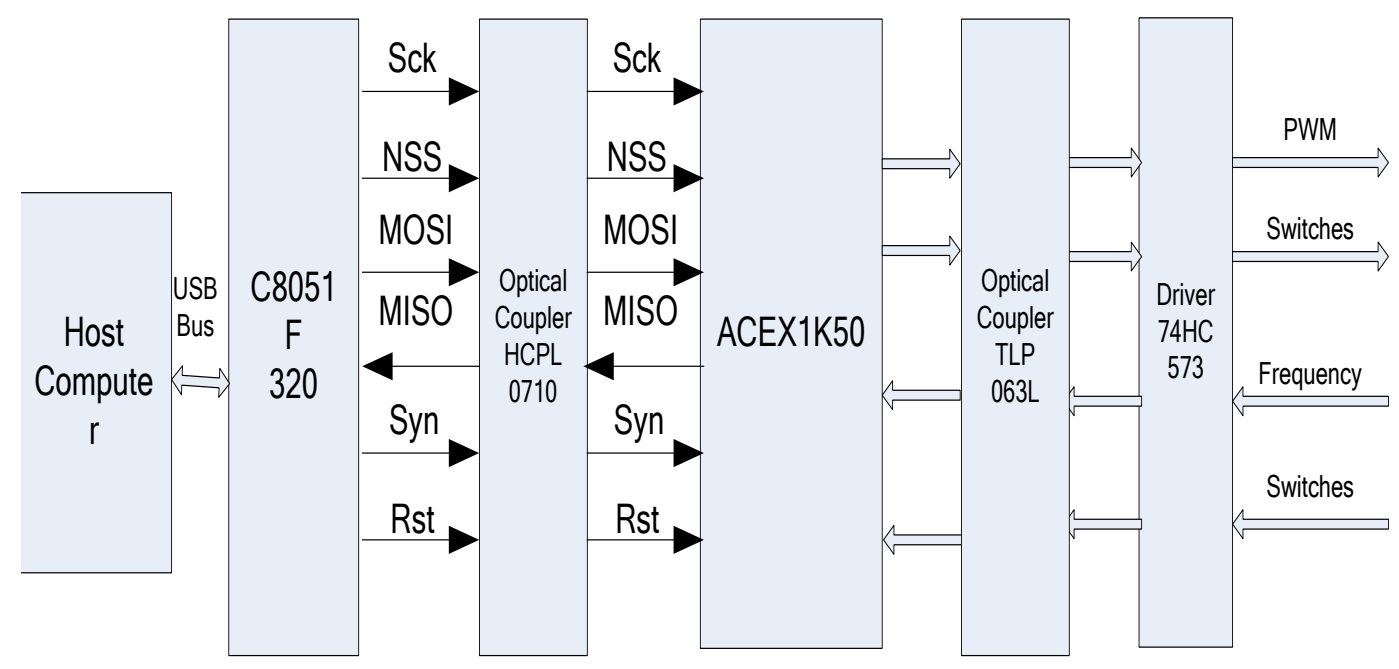

Figure 6. SPI Communication between C8051F320 and FPGA

A/D, D/A Board. A great number of signals such as temperature and pressure signals in aero-engine need to be monitored by electronic controller. And these physical signals are converted to electrical ones by sensor in the engine. The designed simulator makes use of ADuC7020 chip upon ARM inner core to gather electrical modulation signal of the engine and simulates sensor output for gathering of electronic controller. ADuC7020 integrates the functions of A/D and D/A and the circuit board design is relatively simple. Four-way analog acquisition and Four-way analog output are set in FPGA board, a part of SPI bus[6,7]. In addition, UART interface and I2C interface are set in this electric circuit. To achieve the maximum isolation effect, linear optoelectronic isolation devices are adopted to effectively isolate the analog signal. Hardware ligature block diagram of board is shown in Fig. 7.

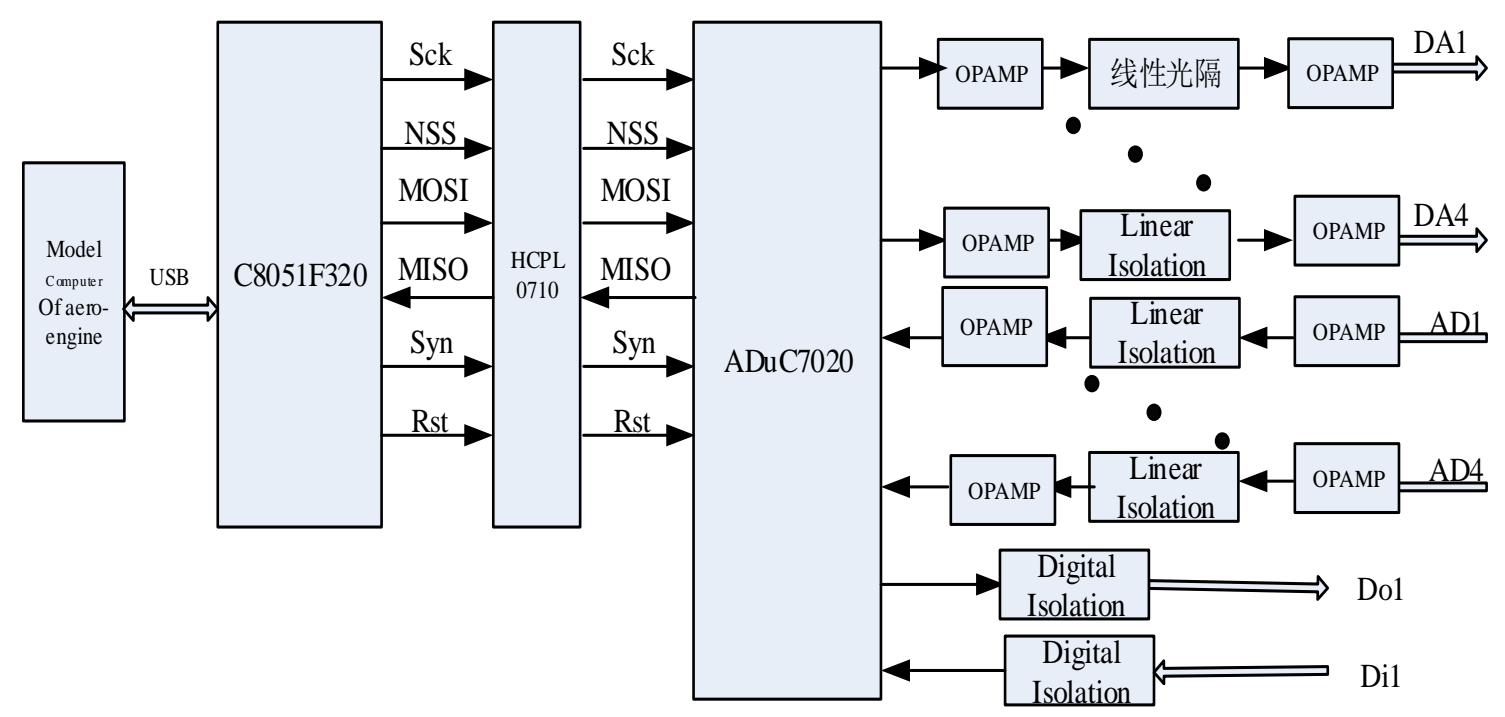

Figure 7. Hardware ligature functional block diagram of $\mathrm{A} / \mathrm{D}$ and $\mathrm{D} / \mathrm{A}$ board

\section{Design of SPI Communication with CRC Code}


The communication interaction circuit between the main control system and signal conditioning circuit is described. The SPI bus communication type is adopted between C8051F320 and FPGA. The speed and accuracy of datum transfer must be considered in the communication design, so the CRC calibration is used.

The communication program based on VHDL is developed by modular design method in ACEX1K50, as shown in Fig. 8. Inner structure design can be divided into several big modules, measure frequency module, data synthesis module, check code encoding modules, SPI communication module, the $\mathrm{CRC}$ check module, packet split module, frequency signal generation module[8].

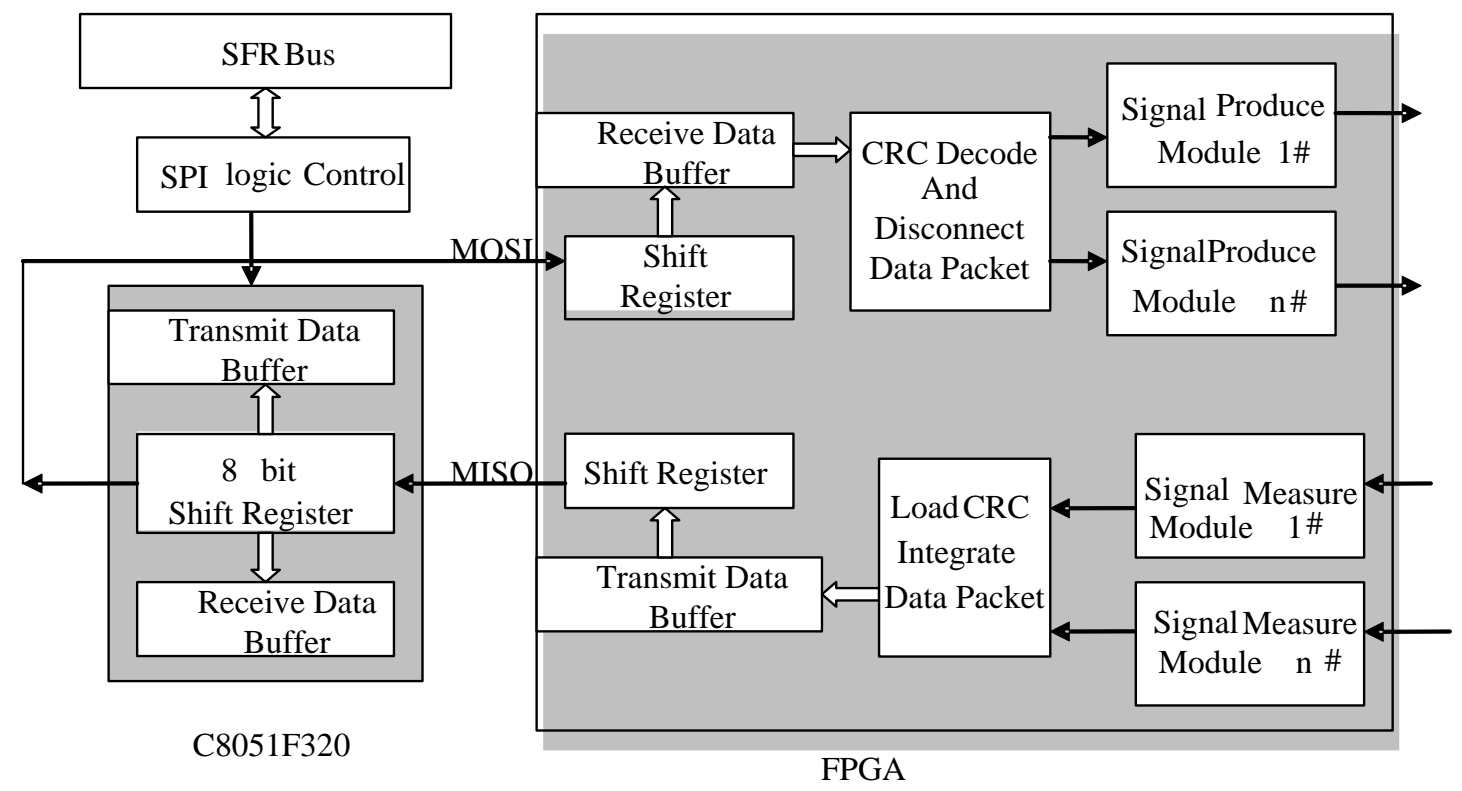

Figure 8. SPI Communication on FPGA

The SCK is configured line low in idle state by program. Data centered master chip C8051F on second edge of SCK period. Slave chip FPGA as shown in Fig. 9.So realized the master-slave chips timing consistency, avoiding mistake by caused timing confusion [9].

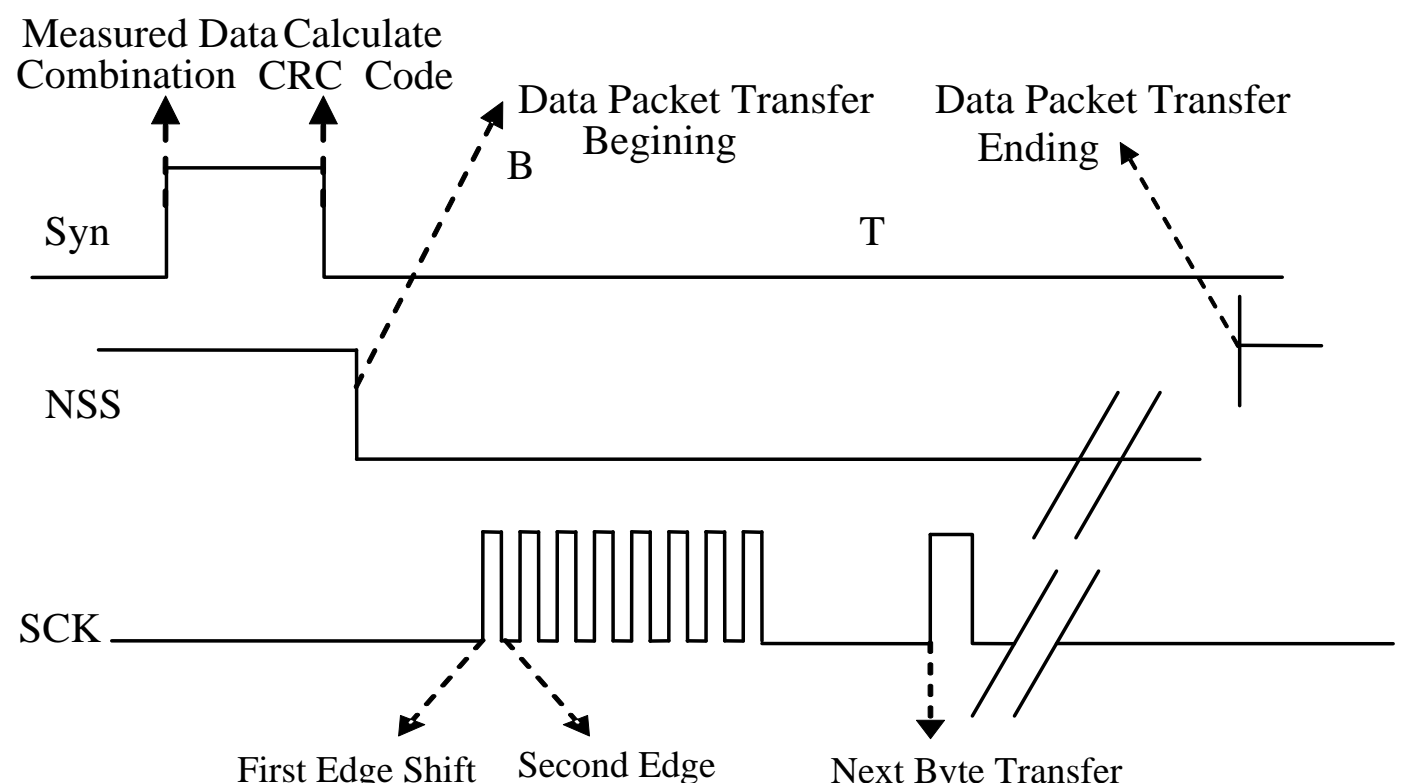

First Edge Shift Second Edge Next Byte Transfer output MISO Acquire MOSI

Figure 9. Timing sequence of SPI communication on FPGA 


\section{System Simulation}

Simulator has monitored the experiment through interface communication of upper and lower computers. Verified simulation result of a certain-type engine controller is shown in Fig. 10. Eight curves in the figure respectively represent the real running conditions of thrust Fn, oil consumption rate of fuel oil sfc, low and high pressure rotor speed N1 and N2, total pressure P6 and total temperature $\mathrm{T} 6$ at the exit of low-pressure turbine, total pressure P3 and total temperature $\mathrm{T} 3$ behind the high-pressure compressor to show that the correctness in design thought of hardware-in-loop simulator of engine has met the requirement of design performance index.

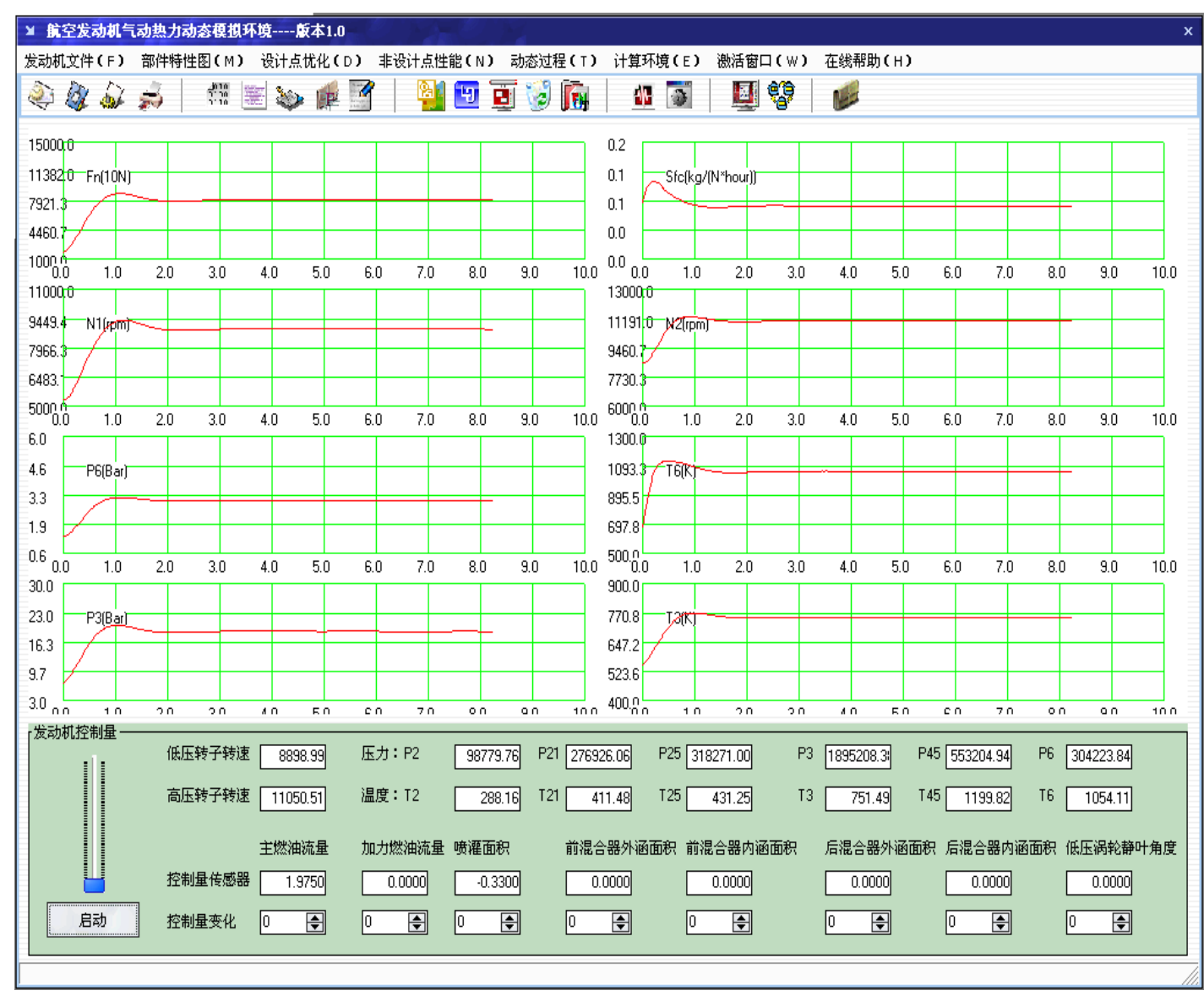

Figure 10. Simulation curves when throttle lever angle of engine is $75^{\circ}$

\section{Conclusions}

Aero-engine emulation technique is an important direction for engine development. The designed hardware-in-loop simulation hardware system of aero-engine absorbs four current advanced microprocessor technique, including main control chip upon PC104 board, chip of C8051F320, ADuC7020 upon ARM inner core and FPGA chip ACEX1K50. Aero-engine emulation technique represents the recent direction of CPU development and probes into the possibility of employing advanced microprocessor into the aero-engine engine control field. Research methods and achievements with practical value are provided to create new technology project. Signal conditioning interface box and communication program of electronic controller interface are created based on $\mathrm{C}$ language and docking experiment has been done on the hardware platform. The designed hardware-in-loop simulation hardware system of aero-engine has been put into use. As long as all 
kinds of status signals and the correctness and speediness of signal transmission control of engines are ensured[10], accuracy of engine digital model and reliability of control algorithm can be effectively verified.

\section{Acknowledgements}

Supported by National Aerospace Science Foundation of China (Fund number: 2014ZB56002)

\section{References}

[1] S.Q. Fan etc: Aircraft engine control (Northwestern Polytechnical University,2008)

[2] X. WANG, J. YANG and D.L. TAN etc: Journal of Aerospace Power, 2005. 20(4):679-683.

[3] S. Pan and J.Y. Huang: EDA Technology Practical Tutorial (Science Press, China 2002)

[4] Z.Z. Xia and Q.F. Chai: Computer \& Digital Engineering, 2005.No.7,p.104

[5] N. Y. Cheng, N. X. Hu, N. X. Chen, and N. P. Li: International Symposium on Electrical Insulating Materials (Japan, June 5-9,2005). Vol.2, p.486-489.

[6] A. Szekacs, T. Szakall and Z. Hegykozi: (2007). International Symposium on Intelligent Systems and Informatics (Subotica, Serbia, 24-25 August, 2007). p.213 - 216.

[7] J. A. Davis, M. Mowbray and S. Crouch: IEEE Transactions on Communications, 1998.46(10), 1250-1253.

[8] D. Audino, F. Baronti, A. Lazzeri, R. Roncella and R. Saletti: 10th Euromicro Conference on Digital System Design Architectures, Methods and Tools (IEEE Computer Society, 2007)

[9] Bei Yang, Jian Li: ICCDA 2011 3rd International Conference on Computer Design and Applications (Xi'an, China, May 27-29, 2011). Vol. 7, p.370.

[10] M. Prabhakar, G. Venkatachalam, et al: AIAA Modeling and Simulation Technologies Conference and Exhibit (2001) Vol.80, pp.315-9. 